\title{
Combining a Droplet-based Microfluidic Tubing System with Gated Indicator Releasing Nanoparticles for Mercury Trace Detection
}

\author{
Jérémy Bell, Estela Climent, Mandy Hecht, Merwe Buurman and Knut Rurack* \\ Bundesanstalt für Materialforschung und -prüfung (BAM) \\ Richard-Willstätter-Str. 11, D-12489 Berlin, Germany \\ knut.rurack@bam.de
}

\section{Supporting Information}

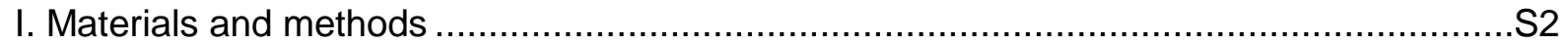

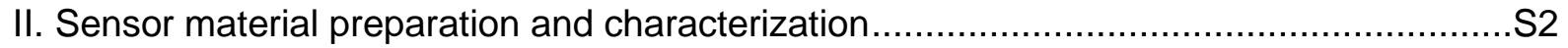

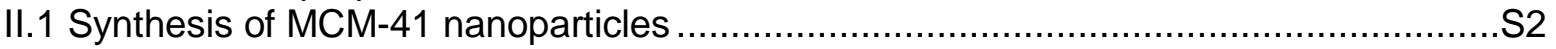

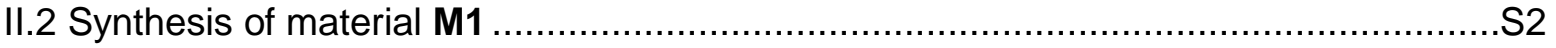

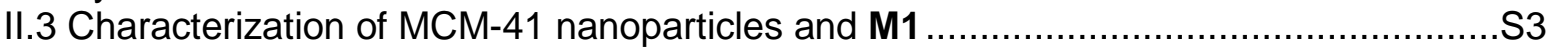

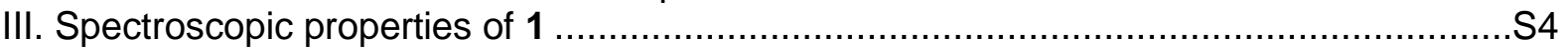

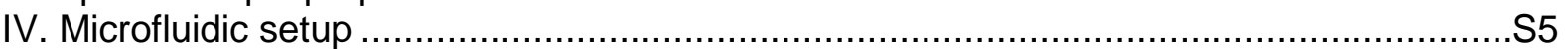

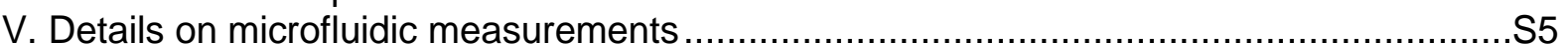

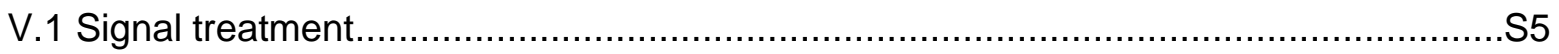

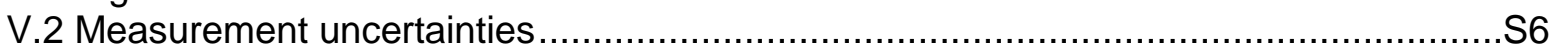

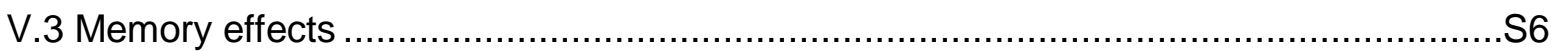

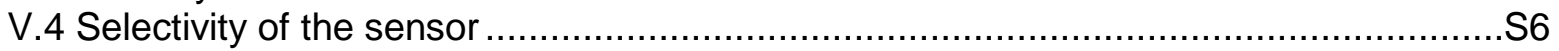

V.5 Hg determination in complex sample matrix: Fish tissue extracts............................S7

V.6 Comparison with a representative selection of other recent methods........................S7

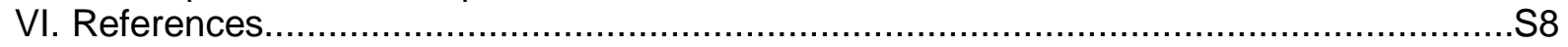




\section{Materials and methods}

All reagents were obtained from commercial suppliers and were used without further purification unless otherwise indicated. For assays which were carried out in various buffer solutions, the following parameters were used: Acetate buffer $(\mathrm{pH}=5)$, MES (2-( $N$-morpholino)ethanesulfonic acid) buffer $(\mathrm{pH}=6)$, phosphate buffer $(\mathrm{pH}=7)$, phosphate buffered saline (PBS, $\mathrm{pH}=7.3)$ and TRIS buffer $(\mathrm{pH}=8)$ at $50 \mathrm{mM}$, and $\mathrm{HCl}$ at $3 \mathrm{mM}(\mathrm{pH}=2.5)$ as well as $\mathrm{NaOH}$ at $0.1 \mathrm{mM}(\mathrm{pH}=10)$.

Absorption spectra were recorded on an Analytik Jena Specord 210 Plus spectrophotometer. Steady-state fluorescence measurements were carried out on a FluoroMax-4 spectrofluorometer from Horiba Jobin-Yvon using standard $10 \mathrm{~mm}$ path length quartz cells.

The fluorescence quantum yields $\left(\phi_{\mathrm{F}}\right)$ were determined as described in ref. 1 . The fluorescence spectra presented here were spectrally corrected.

\section{Sensor material preparation and characterization}

\section{II.1 Synthesis of MCM-41 nanoparticles ${ }^{2}$}

$\mathrm{N}$-Cetyltrimethylammoniumbromide (CTAB, $1.0 \mathrm{~g}, 2.74 \mathrm{mmol}$ ) was dissolved in $480 \mathrm{~mL}$ of deionized water before addition of $3.5 \mathrm{~mL} \mathrm{NaOH}(2.0 \mathrm{M})$ in deionized water, followed by increasing the solution temperature to $80^{\circ} \mathrm{C}$. TEOS $(5.0 \mathrm{~mL}, 25.7 \mathrm{mmol})$ was then added dropwise to the surfactant solution. The mixture was stirred for $2 \mathrm{~h}$ to give a white precipitate. The solid product was centrifuged, washed with deionized water and ethanol, and dried at $60{ }^{\circ} \mathrm{C}$ overnight yielding as-synthesized MCM-41.

In a second step, the surfactant was removed by $\mathrm{HCl} / \mathrm{EtOH}$ extraction. For this purpose, $1.0 \mathrm{~g}$ of the solid previously prepared was suspended in $100 \mathrm{~mL}$ of $\mathrm{HCl}(1 \mathrm{M})$ in $\mathrm{EtOH}$ and the suspension was stirred at $80^{\circ} \mathrm{C}$ for $15 \mathrm{~h}$ in order to remove the surfactant from the pores of the material. After filtering off the solid, it was washed with water until neutral $\mathrm{pH}$ and dried at $60^{\circ} \mathrm{C}$ for $12 \mathrm{~h}$ yielding the MCM-41 scaffold nanoparticles.

\section{II.2 Synthesis of material M1}

As depicted in Figure S1, MCM-41 nanoparticles $(5 \mathrm{mg})$ and dye $1(4 \mu \mathrm{mol})$ were suspended in acetonitrile (ACN, $0.25 \mathrm{~mL}$ ) in an inert atmosphere. Subsequently, the suspension was stirred for $24 \mathrm{~h}$ at room temperature with the aim to achieve maximum loading of the pores of the MCM-41 scaffold. Afterwards, $8 \mu \mathrm{L}$ of 3mercaptopropylmethoxysilane (MPTS, $196.34 \mathrm{~g} \mathrm{~mol}^{-1}, 1.057 \mathrm{~g} \mathrm{~mL}^{-1}, 0.04 \mathrm{mmol}$ ) were added and the final mixture was stirred for $6 \mathrm{~h}$ at room temperature. This sequence guarantees that MPTS diffusion into the pores is hampered and functionalization occurs primarily at the outer surface. After centrifugation and removal of the acetonitrile, the solid was suspended in $1 \mathrm{~mL}$ of a mixture of 1:5 v/v acetonitrile-TRIS buffer $(\mathrm{pH} 8)$ and the squaraine $2(30 \mu \mathrm{L}, 1.5$ $\mathrm{mM}$ in $\mathrm{ACN}$ ) was added to the suspension, where after stirring was continued for $5 \mathrm{~min}$. Finally, the solution was centrifuged, the solvent removed and the particles were washed with acetonitrile $(2 \times 0.5 \mathrm{~mL})$ and dried.
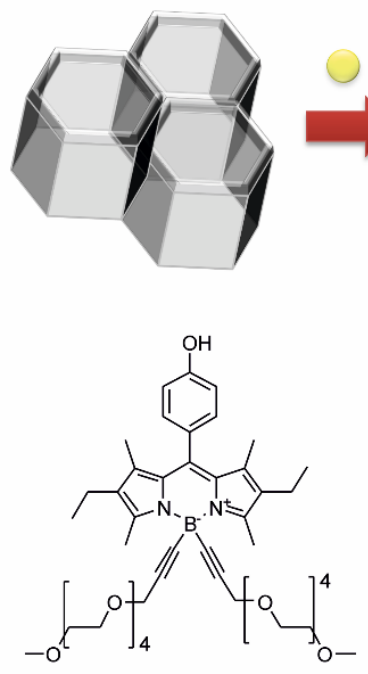

PEGylated BODIPY 1
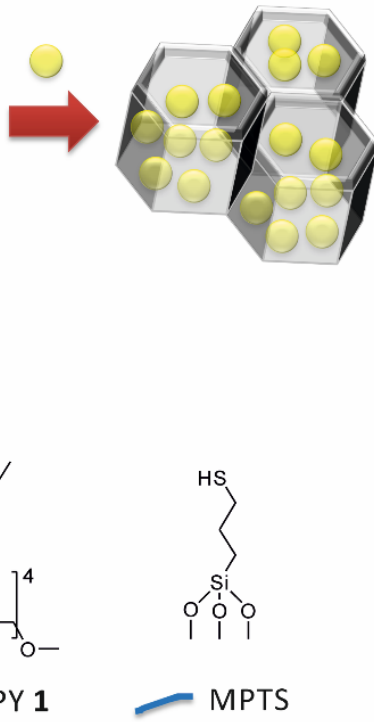
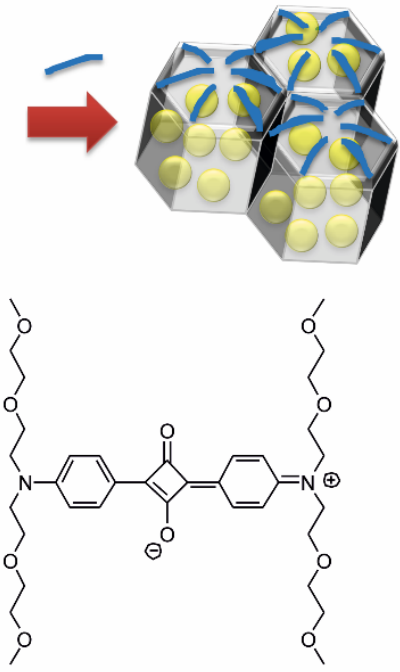

- Squaraine 2
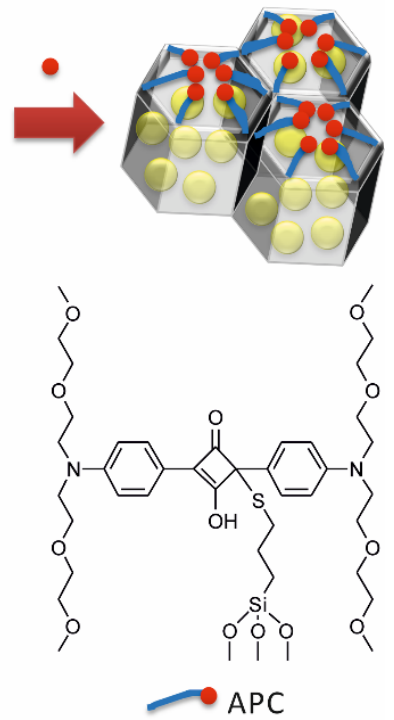

Figure S1. Schematic representation of the synthesis steps leading to M1; the chemical structures of $\mathbf{1}$, squaraine 2, MPTS and the resulting thiol-squaraine adduct (APC) are also shown. 


\section{II.3 Characterization of MCM-41 nanoparticles and M1}

MCM-41 nanoparticles and material M1 were characterized using standard procedures. The structure of the mesoporous MCM-41 particles was confirmed through $\mathrm{N}_{2}$ adsorption-desorption and Transmission Electron Microscopy (TEM) techniques. The $\mathrm{N}_{2}$ adsorption-desorption isotherms of the nanoparticulated MCM- 41 calcined material show an adsorption step at intermediate $P / P_{0}$ value (0.1-0.3) typical for such solids (Figure $S 2$, red curve). This step reflects nitrogen condensation inside the mesopores by capillary forces. The absence of a hysteresis loop in this interval and the narrow BJH pore distribution suggest the existence of uniform cylindrical mesopores with a pore volume of $1.19 \mathrm{~cm}^{3} \mathrm{~g}^{-1}$. A pore diameter of $2.55 \mathrm{~nm}$ was calculated employing the $\mathrm{BJH}$ model on the adsorption branch of the isotherm. The application of the BET model resulted in a value for the total specific surface area of $969.8 \mathrm{~m}^{2} \mathrm{~g}^{-1}$. In addition to this adsorption step associated to the micelle-generated mesopores, a second feature appears in the isotherm at a high relative pressure $\left(P / P_{0}>0.8\right)$. This adsorption corresponds to the filling of the large voids among the particles, presenting a volume of $0.26 \mathrm{~cm}^{3} \mathrm{~g}^{-1}$ (calculated by using the BJH model) and being ascribed to textural porosity. In this case, the curves show a characteristic $\mathrm{H} 1$ hysteresis loop and a wide pore size distribution (see also inset in Figure S2). The presence of the mesoporous structure is also confirmed by TEM analysis (see Figure S2), in which the typical channels of the MCM-41 matrix are visible as alternating black and white stripes. The typical hexagonal porosity of the extracted MCM-41 can also be observed. The figure also shows that the prepared MCM-41 nanoparticles are obtained as spherical particles with diameters ranging from 80 to $100 \mathrm{~nm}$. Moreover, dynamic light scattering (DLS) yielded hydrodynamic volumes of ca. $120 \mathrm{~nm}$ for the materials prepared (Figure S3). Figure S3 also shows that extracted MCM-41 and final material M1 form aggregates of ca. 0.5-1 $\mu \mathrm{M}$. However, only about $5 \%$ of the total particles are in the aggregated state.

M1 shows a typical $\mathrm{N}_{2}$ adsorption-desorption isotherm of mesoporous systems with filled mesopores (Figure S2, black curve). As can be seen, this solid shows flat curves when compared (at the same scale) to those of the MCM41 parent material. This indicates a significant pore blocking and the subsequent absence of appreciable mesoporosity. BJH and BET models allow us to determine a pore volume of $0.61 \mathrm{~cm}^{3} \mathrm{~g}^{-1}$ and a surface area of 620 $\mathrm{m}^{2} \mathrm{~g}^{-1}$, which is significantly lower in comparison to the MCM-41 nanoparticles. Additionally, a certain textural porosity is preserved. BET specific surface values, pore volumes, and pore sizes calculated from the $\mathrm{N}_{2}$ adsorptiondesorption isotherms for MCM-41 nanoparticles and $\mathbf{M 1}$ are listed in Table S1.

A)

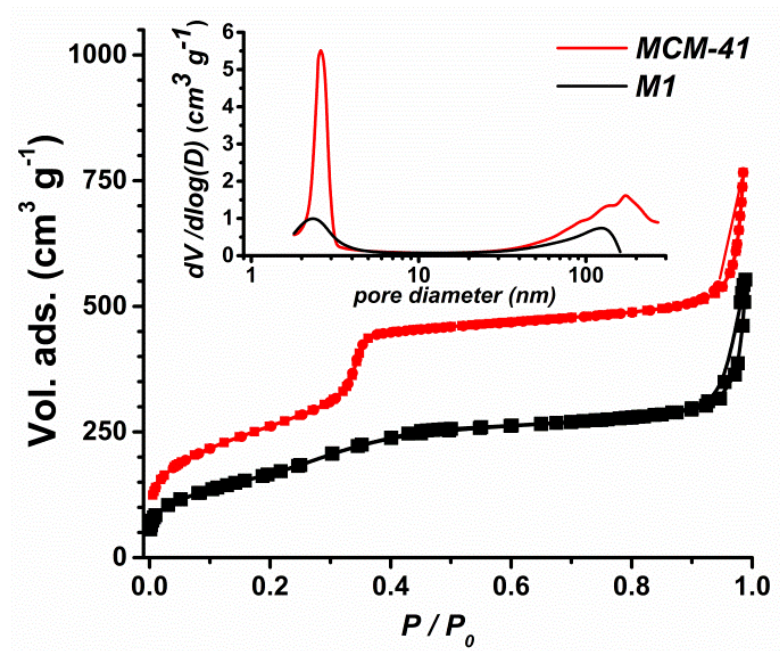

B)

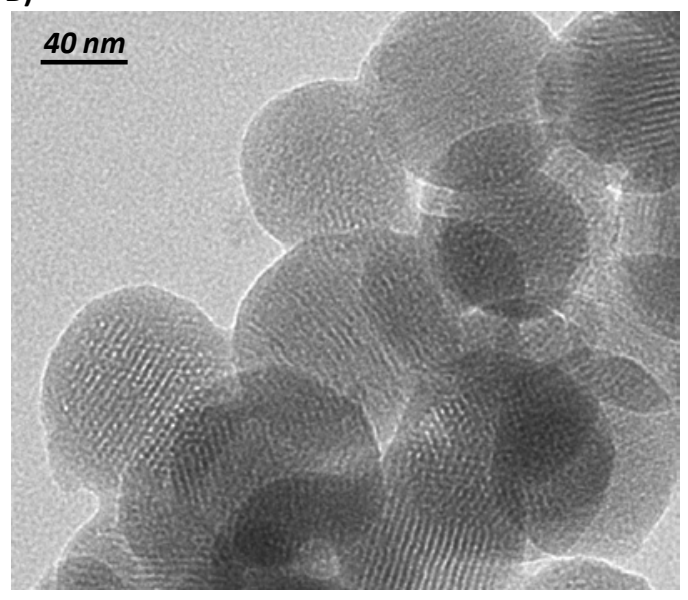

Figure S2. A) Nitrogen adsorption-desorption isotherms for MCM-41 mesoporous material (red) and M1 (black). Inset: Pore size distribution of MCM-41 mesoporous material and M1. B) TEM image of MCM-41 mesoporous material.

Table S1. BET specific surface values, pore volumes and pore sizes calculated from the $\mathrm{N}_{2}$ adsorption-desorption isotherms for selected materials.

\begin{tabular}{cccc} 
Particles & $\begin{array}{c}\boldsymbol{S}_{\mathrm{BET}} \\
\left(\mathrm{m}^{2} \mathrm{~g}^{-1}\right)\end{array}$ & $\begin{array}{c}\text { Pore Volume } \\
\left(\mathrm{cm}^{3} \mathrm{~g}^{-1}\right)\end{array}$ & $\begin{array}{c}\text { Pore size }^{a} \\
(\mathrm{~nm})\end{array}$ \\
\hline MCM-41 & 969 & 1.19 & 2.55 \\
M1 & 620 & 0.61 & - \\
\hline a Volume $(V)$ and diameter $(D)$ of mesopore. & &
\end{tabular}

a Volume (V) and diameter (D) of mesopore. 


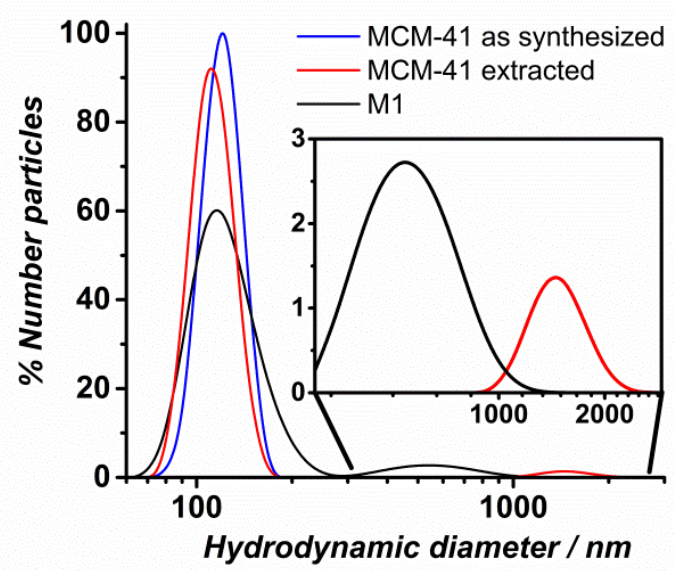

Figure S3. Size distribution by number of particles obtained by DLS studies for MCM-41 as synthesized support, extracted and $\mathbf{M} \mathbf{1}$.

The contents of free MPTS and APC groups as well as $\mathbf{1}$ in the prepared solid M1 were determined by elemental analysis. Taking into account amounts of $\mathrm{C}, \mathrm{N}, \mathrm{H}$, and $\mathrm{S}$ found $(\mathrm{C}, 4,72 ; \mathrm{H}, 1,31 ; \mathrm{N}, 0,37 ; \mathrm{S}, 0,24 \%$ ), contents of 33, 42 and $91 \mu \mathrm{mol} \mathrm{g} \mathrm{solid}^{-1}$ were estimated for free MPTS, APC and 1 units, respectively.

\section{Spectroscopic properties of 1}

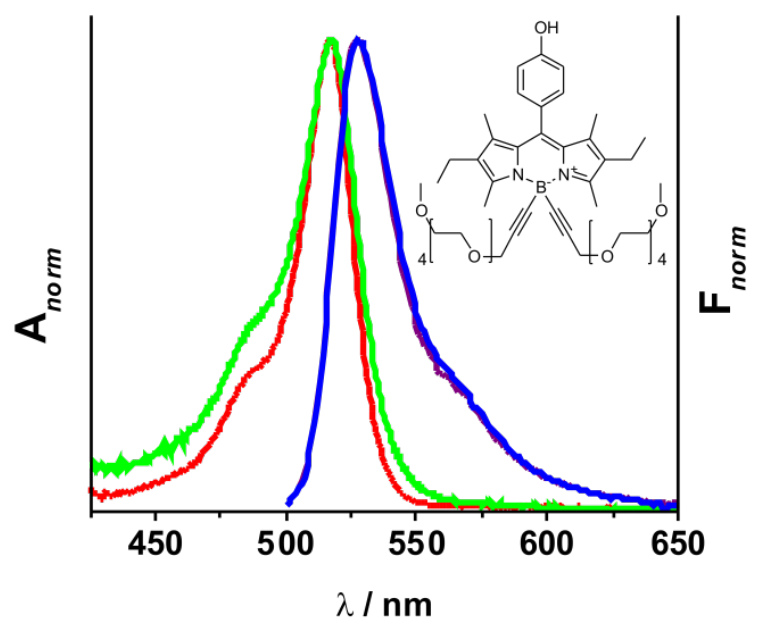

Figure S4. Normalised absorption and emission spectra of $\mathbf{1}$ in water (green/blue) and dichloromethane (red/purple)

Table S2. Photophysical properties of $\mathbf{1}$ in water and dichloromethane

\begin{tabular}{ccccc} 
Solvent & pKs & $\begin{array}{c}\lambda_{\max } \text { abs. } \\
(\mathrm{nm})\end{array}$ & $\begin{array}{c}\lambda_{\max } \text { em. } \\
(\mathrm{nm})\end{array}$ & $\boldsymbol{\phi}_{\mathrm{F}}$ \\
\hline $\mathrm{H}_{2} \mathrm{O}$ & $9.30 \pm 0.03$ & 517 & 527 & $0.81 \pm 0.02$ \\
$\mathrm{CH}_{2} \mathrm{Cl}_{2}$ & - & 520 & 531 & $0.95 \pm 0.02$ \\
\hline
\end{tabular}




\section{Microfluidic setup}

\section{Microfluidic tubing system and fluorescence detection}

The microfluidic part of the sensor is composed of commercially available PTFE and PFA tubes and fittings. ${ }^{3}$ This modularity offer several advantages in terms of handling and assembly. Two inlet tubes enabled introduction of both analyte and sensor material M1 solutions in the microfluidics system via syringes mounted on a commercial syringe pump stand in vertical position to avoid sedimentation of the sensor particles (Chemyx Fusion 100 Touch). Mixing of the two water phases was initiated in an incubation loop (PTFE, ID $500 \mu \mathrm{m}$ ) via diffusion during $100 \mathrm{~s}$, before injection into a T-shaped microdroplet generator (IDEX P-890 MicroTee). A third inlet tube was directly connected to the droplet generator for injection of the organic phase (dichloromethane) via a syringe mounted on a commercial syringe pump stand (Chemyx Fusion 100 Touch).

As for conventional microfluidic chips, stable and homogenous water droplets were produced with a frequency of $0.8 \mathrm{~Hz}$ and a volume of $270 \pm 16 \mathrm{~nL}$ in a commercial micro T-cross as a result of the shear forces and interfacial tension at the fluid-fluid interface. The continuous organic phase that has the lower interfacial tension with the channel walls was injected in-line with the outlet while the aqueous phase was injected perpendicularly. Mixing of the droplets was achieved by chaotic advection by rolling the outlet tube (PFA, ID $500 \mu \mathrm{m}$ ) in a serpentine shape around a metallic bar $\left(\varnothing_{\text {loops }}=1.8 \mathrm{~mm}\right)$. The efficiency of mixing and extraction was assessed by fluorescence. Moreover, using solvent-resistant and transparent PFA tubing allowed us to build a fluorescence detection setup based on a modular cube with a $90^{\circ}$ angle between excitation and emission. Excitation of the fluorescent molecules was achieved with a light emitting diode (Everlight Opto 264-7SUGC/S400-A4) powered with 3.5V DC. A band pass interferential filter (Semrock FF01-510/42-25) centred at $510 \mathrm{~nm}$ was interposed between the LED and the lens used to focus the beam into the microfluidic tube. Fluorescence light was focused through a bundle of six optical fibers (core diameter $400 \mu \mathrm{m}$, external diameter $440 \mu \mathrm{m}$ ) and collected through a band pass filter (Semrock FF01-590/10425 ) into an Ocean Optics spectrometer USB2000+ ( $t_{\text {int }} 50 \mathrm{~ms}$, linearity, dark current and residual light corrections). Treatment of the fluorescence signal was achieved in two steps. First, like for conventional fluorometers, fluctuations of the light source, here the LED and its power supply, were accounted for by collecting directly the excitation light as a reference into the seventh fiber of the optical fiber bundle trough a short-pass filter (Semrock FF01-440/SP-25). Secondly, the respective fluorescence signals from the organic and aqueous phases were extracted by applying a logic formula (see Section V.). When solely water or dichloromethane were circulating through the tube, there was no detectable fluorescence.

\section{Details on microfluidic measurements}

\section{V.1 Signal treatment}

The extraction of the corresponding signals from the organic and aqueous phases was achieved using the following logic equation and conditions:

$$
I_{F}=I_{0} \times(A \wedge B \wedge C)
$$

Table S3. Conditions for validation of the signal treatment logic equation

\begin{tabular}{lll} 
Organic phase & Aqueous phase & Comments \\
\hline $\mathrm{A}: \mathrm{I}_{0}>\sum_{\mathrm{i}=1}^{100} \mathrm{I}_{0}$ & $A: I_{0}<\sum_{i=1}^{100} I_{0}$ & $\begin{array}{l}\text { Separation in two samples, above and below signal } \\
\text { average over } 100 \text { seconds. }\end{array}$
\end{tabular}

$$
B: \frac{105-\tau}{\sum_{i=1}^{100} \mathrm{~A}}>I_{0}>\frac{105+\tau}{\sum_{i=1}^{100} \mathrm{~A}} \quad B: \frac{85-\tau}{\sum_{i=1}^{100} \mathrm{~A}}<I_{0}<\frac{105+\tau}{\sum_{i=1}^{100} \mathrm{~A}}
$$

Cleaning of the two samples using empiric bounds and a variable rate $\tau$, fixed at 10 for these experiments. Removal of outliers coming from gas bubbles, dust or aggregates.

Second cleaning, value kept only when two successive values were found. Removal of artefacts as a droplet correspond to 3 points. 


\section{V.2 Measurement uncertainties ${ }^{4}$}

The relative errors of the measurements were calculated for each concentration of mercury taking in account the errors coming from:

- Preparation of the solutions: weighting of mercury salt: $u_{r e l}^{w}$, dissolving of mercury in water: $u_{r e l}^{s}$, weighting of particles: $u_{r e l}^{w}$, dissolving of particles in water: $u_{r e l}^{S}$, successive dilution of the mother solution: $n \times u_{r e l}^{d}\left(\left[\mathrm{Hg}^{2+}\right]=0\right.$, $\left.\mathrm{n}=0 ;\left[\mathrm{Hg}^{2+}\right]=1.10^{-4}, \mathrm{n}=0 ;\left[\mathrm{Hg}^{2+}\right]=1.10^{-6}, \mathrm{n}=1 ;\left[\mathrm{Hg}^{2+}\right]=1.10^{-8}, \mathrm{n}=2 ;\left[\mathrm{Hg}^{2+}\right]=1.10^{-10}, \mathrm{n}=3 ;\left[\mathrm{Hg}^{2+}\right]=1.10^{-12}, \mathrm{n}=4\right)$

- Fluorescence analysis and numerical treatment: $u_{r e l}^{a}$

- Repetition of the experiment $(\mathrm{N}=3): u_{r e l}^{r}$

Table S4. Calculation of the relative errors for each mercury solution

$\left[\mathrm{Hg}^{2+}\right]$

Relative error on the measurement

mol. $L^{-1}$ Formula

\begin{tabular}{|c|c|c|}
\hline $10^{-4}$ & $u_{r e l}^{I_{F}{ }^{2}}=u_{r e l}^{w}{ }^{2}+u_{r e l}^{s}{ }^{2}+u_{r e l}^{w}{ }^{2}+u_{r e l}^{s}{ }^{2}+u_{r e l}^{a}{ }^{2}+u_{r e l}^{r}{ }^{2}$ & 6,1 \\
\hline $10^{-6}$ & $u_{r e l}^{I_{F}{ }^{2}}=u_{r e l}^{w}{ }^{2}+u_{r e l}^{s}{ }^{2}+u_{r e l}^{w}{ }^{2}+u_{r e l}^{s}{ }^{2}+u_{r e l}^{d{ }^{2}}+u_{r e l}^{a}{ }^{2}+u_{r e l}^{r}{ }^{2}$ & 9,3 \\
\hline $10^{-8}$ & $u_{r e l}^{I_{F}{ }^{2}}=u_{r e l}^{w}{ }^{2}+u_{r e l}^{s}{ }^{2}+u_{r e l}^{w}{ }^{2}+u_{r e l}^{s}{ }^{2}+u_{r e l}^{d}{ }^{2}+u_{r e l}^{d}{ }^{2}+u_{r e l}^{a}{ }^{2}+u_{r e l}^{r}{ }^{2}$ & 7,1 \\
\hline $10^{-10}$ & $u_{r e l}^{I_{F}{ }^{2}}=u_{r e l}^{w}{ }^{2}+u_{r e l}^{s}{ }^{2}+u_{r e l}^{w}{ }^{2}+u_{r e l}^{s}{ }^{2}+u_{r e l}^{d^{2}}+u_{r e l}^{d^{2}}+u_{r e l}^{d^{2}}+u_{r e l}^{a^{2}}+u_{r e l}^{r}{ }^{2}$ & 6,1 \\
\hline $10^{-12}$ & $u_{r e l}^{I_{F}{ }^{2}}=u_{r e l}^{w}{ }^{2}+u_{r e l}^{s}{ }^{2}+u_{r e l}^{w}{ }^{2}+u_{r e l}^{s}{ }^{2}+u_{r e l}^{d}{ }^{2}+u_{r e l}^{d}{ }^{2}+u_{r e l}^{d}{ }^{2}+u_{r e l}^{d^{2}}+u_{r e l}^{a}{ }^{2}+u_{r e l}^{r}{ }^{2}$ & 6,6 \\
\hline 0 & $u_{r e l}^{I_{F}{ }^{2}}=u_{r e l}^{w}{ }^{2}+u_{r e l}^{s}{ }^{2}+u_{r e l}^{a}{ }^{2}+u_{r e l}^{r}{ }^{2}$ & 4,5 \\
\hline
\end{tabular}

\section{V.3 Memory effects}

Because of the inertness of PTFE and PFA tubing, no major memory effects were observed during the assays. Experiments could be carried out with or without intermediate blanks. Figure S5 shows the stability of the system when assays were repeatedly run by alternating sample and blank control. Furthermore, typical and repeatable stepped titration curves were obtained for various concentrations of mercury ions when running the assay without intermediate blanks.

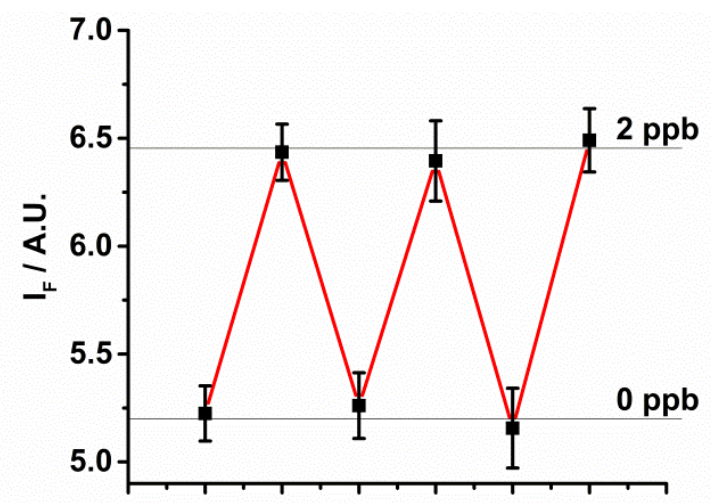

Figure S5. Repetition of $\mathrm{Hg}^{2+}(2 \mathrm{ppb})$ recognition assays by $\mathbf{M} 1$ integrated with the microfluidic system $\left(c_{\mathrm{M} 1}=0.4 \mathrm{~g} \mathrm{~L}^{-1}\right.$; $\mathrm{H}_{2} \mathrm{O} / \mathrm{CH}_{2} \mathrm{Cl}_{2}, 2 / 1, \mathrm{v} / \mathrm{v}$; PBS buffer)

\section{V.4 Selectivity of the sensor}

The selectivity of the sensor towards mercury was controlled by measuring the response of potentially interfering metal ions such as $\mathrm{Na}^{+}, \mathrm{K}^{+}, \mathrm{Ca}^{2+}, \mathrm{Mg}^{2+}$ at $1 \mathrm{mM}, \mathrm{Cu}^{2+}, \mathrm{Ni}^{2+}, \mathrm{Zn}^{2+}, \mathrm{Ag}^{+}, \mathrm{Cd}^{2+}$ at $0.5 \mathrm{mM}, \mathrm{Pb}^{2+}, \mathrm{Au}^{3+}$ at $0.2 \mathrm{mM}$ (as chloride, nitrate, or perchlorate salts) and $\mathrm{Hg}^{2+}$ at $0.1 \mathrm{mM}$, all the solutions being injected through the sample port. As shown in Figure S6, none of these species induced a dramatic increase in the response of $\mathbf{M} 1$ apart from mercury ions. This selectivity profile reflects well our earlier study ${ }^{2}$ and shows the excellent suitability of the approach. 


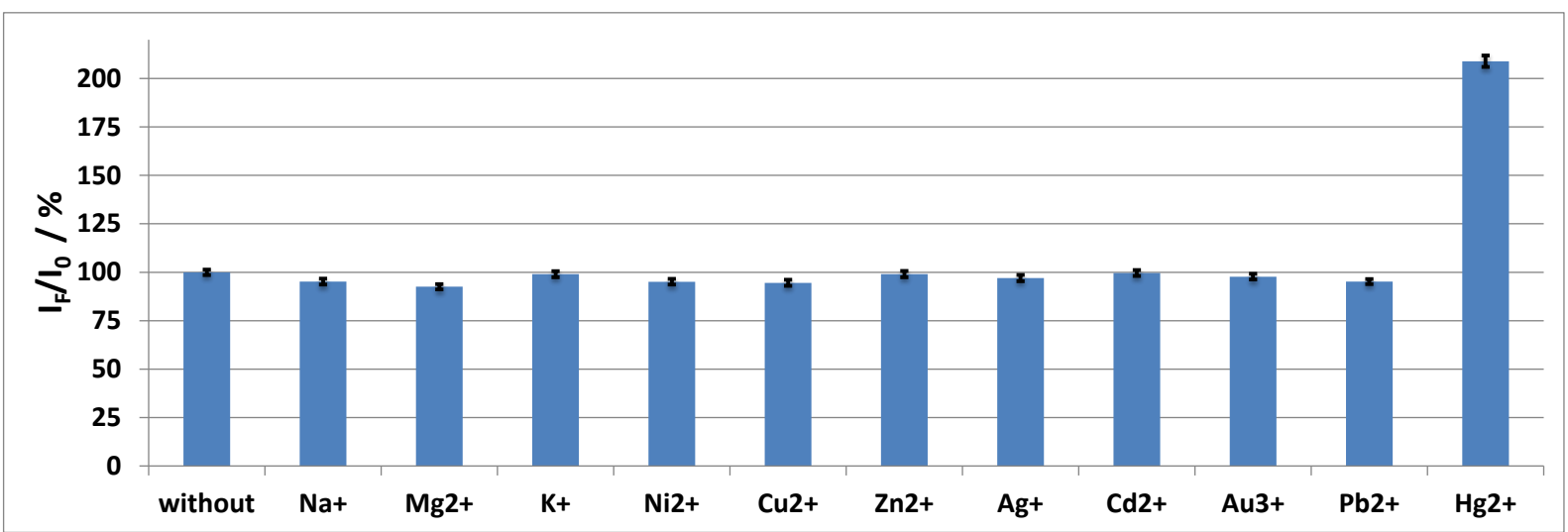

Figure S6. Selectivity and response of the microfluidic sensor towards potentially interfering metal ions $\left(\mathrm{Na}^{+}, \mathrm{K}^{+}\right.$, $\mathrm{Ca}^{2+}, \mathrm{Mg}^{2+}$ at $1 \mathrm{mM} ; \mathrm{Cu}^{2+}, \mathrm{Ni}^{2+}, \mathrm{Zn}^{2+}, \mathrm{Ag}^{+}, \mathrm{Cd}^{2+}$ at $0.5 \mathrm{mM} ; \mathrm{Pb}^{2+}, \mathrm{Au}^{3+}$ at $0.2 \mathrm{mM}$ and $\mathrm{Hg}^{2+}$ at $0.1 \mathrm{mM}$ )

\section{V.5 Hg determination in complex sample matrix: Fish tissue extracts}

Prior to homogenization, tissues from fishes purchased in the local supermarket were crushed and dried on petri dishes overnight at $85^{\circ} \mathrm{C}$. Portions of ca. $0.3 \mathrm{~g}$ were incubated in $2 \mathrm{~mL} \mathrm{HNO}$ (fuming) for $1 \mathrm{~h}$ before addition of $0.5 \mathrm{~mL} \mathrm{HClO}_{4}$ (70\%). Then, the samples were irradiated under a UV lamp for $3 \mathrm{~h}$ (LAR Analytik \& Umweltmeßtechnik $\mathrm{GmbH}$, NI. UO25E5; Tp: PLyser; $1991 \mathrm{~V} 230 \mathrm{KW}$ 0'7) to convert all possibly contained organic mercury to inorganic mercury. Finally, the acid extracts were transferred to $50 \mathrm{~mL}$ volumetric flasks, and the volume was adjusted to 50 $\mathrm{mL}$ with Milli-Q water.Control measurements were carried out on a Mercur ${ }^{\circledR}$ Mercury analyzer from Analytik Jena AG by means of Cold Vapor-Atomic Emission Spectroscopy (CV-AES) using $\mathrm{SnCl}_{2}$ as reducing agent.

For the comparative study, fish tissue extracts were diluted to $\mathrm{Hg}$ levels of ca. $10^{-7} \mathrm{M}$ before known aliquots of mercury were added according to a standard addition method. The initial mercury concentration in the tissues was then determined using linear regression.

Table S5. Mercury concentrations in fish tissue extracts Fish extract

Method developed here

CV-AES $(\mathrm{mg} / \mathrm{kg})$

\begin{tabular}{cccc} 
& $(\mathrm{mg} / \mathrm{kg})$ & $(\mathrm{mg} / \mathrm{kg})$ & $(\%)$ \\
\hline Salmon a & $0.073 \pm 0.005$ & $0.063 \pm 0.004$ & +16 \\
Salmon b & $0.067 \pm 0.004$ & $0.059 \pm 0.001$ & +14 \\
Tuna a & $0.539 \pm 0.042$ & $0.463 \pm 0.001$ & +16 \\
Tuna b & $0.562 \pm 0.036$ & $0.442 \pm 0.001$ & +27 \\
\hline
\end{tabular}

\section{V.6 Comparison with a representative selection of other recent methods}

In comparison with other recently published methods, the one described in this paper shows interesting advantages with regard to response time and LOD (Table S6). Even if one of the methods (see ref. 6) showed a faster response time and a better theoretical sensitivity, the experimental results found with our method demonstrate the actual possibility to detect traces of mercury in practice. Concerning the linearity range, the sensor described here shows also comparable or even better results.

Table S6. Comparison with other recent methods (AuNPs = gold nanoparticles, AuNRs = gold nanorods)

\begin{tabular}{ccccccc} 
Ref & Type of analysis & Method & Sensor & $\begin{array}{c}\text { Response } \\
\text { time (min) }\end{array}$ & LOD (nM) & Linearity (nM) \\
\hline 5 & Test strips & Colorimetric & DNA-AuNPs & 40 & 50 & $25-750$ \\
6 & Laboratory analysis & Colorimetric & Ligands-AuNRs & 5 & $\begin{array}{c}0.015 \\
\text { (estimated) }\end{array}$ & $15-150$ \\
7 & Test strips & Fluorescence & Ligands & 10 & 0.5 & $50-500$ \\
8 & Laboratory analysis & $\begin{array}{c}\text { Single-channel } \\
\text { Electrical chamber }\end{array}$ & ssDNA & 30 & 7 & $7-700$ \\
this publication & Microfluidics setup & Fluorescence & Ligands-MCM41 & $\mathbf{1 0}$ & $\mathbf{0 . 1}$ & $\mathbf{0 . 1}-\mathbf{1 0 0 0}$ \\
\hline
\end{tabular}




\section{References}

1. Opel, J.; Hecht, M.; Rurack, K.; Eiblmeier, J.; Kunz, W.; Colfen, H.; Kellermeier, M. Probing local pH-based precipitation processes in self-assembled silica-carbonate hybrid materials Nanoscale 2015, 7 (41), 17434-17440.

2. Climent, E.; Marcos, M. D.; Martinez-Manez, R.; Sancenon, F.; Soto, J.; Rurack, K.; Amoros, P. The determination of methylmercury in real samples using organically capped mesoporous inorganic materials capable of signal amplification Angew. Chem. Int. Ed. 2009, 48 (45), 8519-8522.

3. Feuerborn, A.; Prastowo, A.; Cook, P. R.; Walsh, E. Merging drops in a Teflon tube, and transferring fluid between them, illustrated by protein crystallization and drug screening Lab Chip 2015, 15, 3766-3775.

4. Rurack, K.; Spieles, M. Fluorescence quantum yields of a series of red and near-infrared dyes emitting at 600-1000 nm Anal. Chem. 2011, 83 (4), 1232-1242.

5. Chen, G.-H.; Chen, W.-Y.; Yen, Y.-C.; Wang, C.-W.; Chang, H.-T.; Chen, C.-F. Detection of mercury(II) ions using colorimetric gold nanoparticles on paper-based analytical devices. Anal. Chem. 2014, 86 (14), 6843-6849.

6. Placido, T.; Aragay, G.; Pons, J.; Comparelli, R.; Curri, M. L.; Merkoçi, A. Ion-directed assembly of gold nanorods: a strategy for mercury detection. ACS Appl. Mater. Interfaces 2013, 5 (3), 1084-1092.

7. Aragay, G.; Monton, H.; Pons, J.; Font-Bardia, M.; Merkoci, A. Rapid and highly sensitive detection of mercury ions using a fluorescence-based paper test strip with an N-alkylaminopyrazole ligand as a receptor. J. Mater. Chem. 2012, 22 (13), 59785983.

8. Wen, S.; Zeng, T.; Liu, L.; Zhao, K.; Zhao, Y.; Liu, X.; Wu, H.-C. Highly sensitive and selective DNA-based detection of mercury(II) with $\alpha$-hemolysin nanopore. J. Am. Chem. Soc. 2011, 133 (45), 18312-18317. 